\title{
Spatial assessment of Langat river water quality using chemometrics
}

\begin{abstract}
The present study deals with the assessment of Langat River water quality with some chemometrics approaches such as cluster and discriminant analysis coupled with an artificial neural network (ANN). The data used in this study were collected from seven monitoring stations under the river water quality monitoring program by the Department of Environment (DOE) from 1995 to 2002. Twenty three physico-chemical parameters were involved in this analysis. Cluster analysis successfully clustered the Langat River into three major clusters, namely high, moderate and less pollution regions. Discriminant analysis identified seven of the most significant parameters which contribute to the high variation of Langat River water quality, namely dissolved oxygen, biological oxygen demand, $\mathrm{pH}$, ammoniacal nitrogen, chlorine, E. coli, and coliform. Discriminant analysis also plays an important role as an input selection parameter for an ANN of spatial prediction (pollution regions). The ANN showed better prediction performance in discriminating the regional area with an excellent percentage of correct classification compared to discriminant analysis. Multivariate analysis, coupled with ANN, is proposed, which could help in decision making and problem solving in the local environment.
\end{abstract}

Keyword: Chemometrics; Artificial neural networks; Spatial assessment; Langat River 